\title{
O IMPACTO DO BRINCAR/ JOGAR EM ATIVIDADES DE TEMPOS LIVRES NO ENVOLVIMENTO, SATISFAÇÃO E INTERAÇÃO DE CRIANÇAS E JOVENS
}

\author{
Paulo César Bulhões \\ FCSH, Universidade dos Açores \\ Ponta Delgada, Açores, Portugal \\ paulo_bulhoes82@hotmail.com \\ Isabel Cabrita Condessa \\ CIEC, Instituto de Educação da Universidade do Minho \\ Braga, Portugal \\ FCSH, Universidade dos Açores \\ Ponta Delgada, Açores, Portugal \\ maria.id.condessa@uac.pt
}

Fecha de Recepción: 8 Agosto 2019

Fecha de Admisión: 25 Septiembre 2019

\section{RESUMO}

Este trabalho teve como propósito perceber o nível de envolvimento das crianças e jovens nas atividades, o seu grau de satisfação e as relações estabelecidas com os colegas e profissionais de educação e foi realizado numa Instituição Particular de Solidariedade Social (IPSS)", em seis valências CATL - Centros de Atividades de Tempos Livres, onde se priorizavam nas propostas diárias a ludicidade e o direito a brincar/jogar.

Nesta nossa investigação, de natureza exploratória e com caraterísticas qualitativas, efetuámos um cruzamento de informação obtida pelo recurso a técnicas variadas e complementares: análise documental; observações participantes (entrevistas informais e recolhas de imagens); entrevistas semiestruturadas (individuais e em grupo - Focus Group). Para o tratamento de dados realizou-se a análise de conteúdo e serão aqui apresentados alguns excertos dos discursos realizados - observadores e entrevistados.

Verificámos que a participação das crianças e jovens no âmbito das atividades de tempos livres é positiva e valorativa, mediante um conjunto de oportunidades educativas e socioculturais, que reforçam o papel colaborativo e de mediação do profissional de educação, o respeito pela voz ativa da criança/ jovem e, muitas vezes, pelas diferenças individuais, onde se realçam as questões de género. A satisfação das mesmas depende das relações com os colegas e profissionais, das oportunidades e dos interesses institucionais associados. As relações estabelecidas com os colegas proporcionam enriquecimento e interajuda, afetos, novas aprendizagens, enquanto que as relações com os profissionais possibilitam proteção, respeito e proximidade. 


\section{O IMPACTO DO BRINCAR/ JOGAR EM ATIVIDADES DE TEMPOS LIVRES NO ENVOLVIMENTO, SATISFAÇÃO E INTERAÇÃO DE CRIANÇAS E JOVENS}

Ainda se concluiu que os CATL, da IPSS em estudo, assentam na gestão de dois conceitos: ludicidade e liberdade, com enfoque principal no brincar, enquanto constructo de desenvolvimento pessoal, social e educativo da criança/ jovem. No âmbito das atividades de tempos livres, promovidas pelas valências em estudo, há uma valorização da criança, enquanto sujeito de direitos - expressão, tempos livres, repouso, participação, segurança, recreação, lazer, educação.

Palavras-chave: atividades de tempos livres; crianças; jovens; brincar/jogar; direitos.

\section{ABSTRACT}

The impact of play on free time activities in child and youth involvement, satisfaction and interaction. This work aimed to understand the level of involvement of children and young people in the activity, their satisfaction and the relationships established with colleagues and education professionals and was conducted in a Private Social Solidarity Institution (PSSI) ", in six valences FTAC - Free Time Activities Centers, where daily proposals were given priority over playfulness and the right to play.

In our research, a exploratory study with qualitative characteristics, we crossed information obtained through the use of varied and complementary instruments: document analysis; participating observations (informal interviews and image collections); semi-structured interviews (individual and group - Focus Group). For data treatment, content analysis was performed and some excerpts of the speeches made - observers and interviewees will be presented here.

We found that the participation of children and youth in the scope of leisure activities is positive and value, through a set of educational and socio-cultural opportunities, which reinforce the collaborative and mediation role of the education professional, the respect for the active voice of the child. often by individual differences, where gender issues are highlighted. Their satisfaction depends on relationships with colleagues and professionals, opportunities and associated institutional interests. The relationships established with colleagues provide enrichment and mutual help, affection, new learning, while relationships with professionals enable protection, respect and closeness.

It was also concluded that the FTACs of this research are based on the management of two concepts: playfulness and freedom, with a main focus on play, as a construct of personal, social and educational development of the child / youth. In the scope of the leisure activities, promoted by the valences under study, there is an appreciation of the child, as subject of rights - expression, leisure, rest, participation, security, recreation, leisure and education.

Keywords: leisure activities; children; young; play; rights.

\section{INTRODUÇÃo}

A criança possui um papel essencial na promoção das atividades de tempos livres e de lazer, tornando-se pertinente a reflexão sobre o seu envolvimento e valorização. Para Silva e Sarmento (2017), é fundamental valorizar a criança como sujeito de direitos, nomeadamente na participação ativa da infância e na brincadeira. Segundo tais visões, a criança no papel de ator, conquista a sua presença, determinação, participação e satisfação nas atividades relacionadas com a sua infância, bem como nas relações estabelecidas com os outros.

As crianças estão sempre em constantes aprendizagens e interações, o que determina a sua ação e reflexão acerca da realidade. 0 percurso de conquista do estado de direitos das crianças ocorreu gradualmente, ao longo da história, pois segundo Soares (2005), as crianças no decorrer dos anos têm feito uma procura dos seus direitos e do reconhecimento da sua voz, face ao papel dos adultos, pois estes "decidem acerca das suas vidas, nomeadamente os seus pais" (p. 1). Porém, durante muito tempo as crianças foram tidas como sendo "irresponsáveis, irracionais e incapazes 
de fazer escolhas informadas" (p. 2), precisando de apoio e proteção. Para a autora, é fulcral ver a criança à luz de um conjunto de direitos, que se situam em "direitos pessoais e sociais" (p. 4), defendidos pela Convenção dos Direitos da Criança (CDC), adotada pela Assembleia Geral nas Nações Unidas em 20 de novembro de 1989 e ratificada por Portugal em 21 de setembro de 1990.

De acordo com a CDC (2004), a criança conquista um papel decisivo na forma como 0 adulto e a sociedade se deverá relacionar com ela, apoiada por diversos artigos transversais a várias áreas de apoio ao seu crescimento, como a educação, a saúde, a igualdade, a proteção, a justiça, a família, etc. 0 referido documento reconhece 0 direito que qualquer criança possui face aos tempos livres, ao repouso, ao lúdico e ao lazer (artigo 31ํㅜㄹ ponto 1). Estes deverão ver vividos de forma livre e informada, o que ajuda a construir "cidadãs ativas" (Tomás, 2007, p. 121).

Os direitos da própria criança têm na atualidade algumas limitações, pré-definidas pelo adulto, sociedade e organizações, uma vez que o seu tempo se encontra demasiadamente estruturado com "tempo de acordar, tempo de comer, tempo de ir à escola, tempo de brincar, tempo livre, tempo de dormir" (Araújo, 2009a, p.48), havendo uma despreocupação, por parte dos adultos, com as potencialidades educativas de cada espaço. Para Silva e Sarmento (2017) 0 adulto tende a estruturar 0 tempo livre da criança, condicionando a sua liberdade e ação, através das suas escolhas.

Hoje, a mesma criança desempenha vários ofícios, construindo, assim, o "ofício da criança", segundo Sarmento (2011), o que pressupõe a construção de outros ofícios, como o "ofício do aluno", por ação da escola, e "e-ofício da criança", fruto das tecnologias de informação e comunicação. Embora o papel e o saber da criança possa ser construído socialmente, pelas suas aprendizagens, atitudes, comportamentos e valores, por isso ao "ofício da criança" torna-se fulcral dar destaque ao brincar, tendo em conta o seu papel na infância, uma vez que segundo Sarmento (2003) "brincar é a condição da aprendizagem e, desde logo, da aprendizagem da sociabilidade" (p. 12), pois pelo brincar há o "conhecimento de si próprio, do mundo físico e social e dos sistemas de comunicação" (Araújo, 2009a, p. 132).

A criança possui os "seus direitos limitados: não podem correr à vontade, gritar, escrever nas paredes, saltar, cantar alto, fazer barulho (...), subir às árvores” (Araújo, 2006, p. 17). Neto (2004), também refere que é fundamental apostar pedagogicamente em atividades de ar livre, aventura e descoberta, seja em ambiente rural ou até urbano. Para o autor, este desafio é transversal a todos os "parceiros" que circundam a criança.

Inserida nas "culturas das infâncias" surge um destaque especial à capacidade do jogo e seus impactos no desenvolvimento da aprendizagem e construção de relações sociais (Sarmento, 2003), sendo o brincar considerado como um direito de toda e qualquer criança, independentemente do contexto de onde são oriundas. 0 brincar apresenta um conjunto de vantagens ao nível do desenvolvimento físico e psicológico da criança.

0 direito ao brincar deverá ser uma preocupação das instituições que ocupam o tempo de lazer das crianças, tentando criar estruturas e dinâmicas adaptadas às suas caraterísticas, pois segundo Sequeira e Pereira (2004), é fundamental inventarem "novos A.T.L. onde a opinião das crianças seja lei e 0 brincar um direito de todas as crianças" (p. 15). Neste ponto de vista a criança deverá ser vista como "um actor em contínuo desenvolvimento e com opinião própria e pontos de vista que importa ter em consideração" (Tomás, 2007, p. 122), valorizando a sua participação e a "socialização como um processo dinâmico e dual" (p. 122). Para Silva e Sarmento (2017), as instituições deverão preocupar-se em responder às necessidades das crianças, criando condições para a promoção do lazer e do lúdico.

A maior institucionalização das crianças, na atualidade, traz desafios para as próprias instituições e profissionais de educação, na medida em que têm de criar condições para que o tempo da 


\section{O IMPACTO DO BRINCAR/ JOGAR EM ATIVIDADES DE TEMPOS LIVRES NO ENVOLVIMENTO, SATISFAÇÃO E INTERAÇÃO DE CRIANÇAS E JOVENS}

brincadeira seja um tempo pleno e de lazer. Para Neto (2000), a espontaneidade do brincar tem vindo a sofrer mudanças, estando em extinção o brincar na rua e os jogos tradicionais/ populares. Por sua vez, verifica-se, segundo o autor, uma maior organização e estruturação das atividades, com implicações negativas na autonomia e desenvolvimento motor e emocional da criança. A institucionalização do brincar poderá criar novas "barreiras" à brincadeira livre, tornando-se uma consequência da modernidade.

Para a criança a brincadeira assume uma dimensão intemporal, por meio de relações e partiIhas, pois para esta o mais importante é o presente, a liberdade e o sentido atribuído pela mesma (Costa, Kuhn \& Cunha, 2015).

No âmbito das relações que a criança estabelece é fundamental haver a valorização do seu papel e da sua participação, seja com os adultos ou com os seus pares, pois segundo Lansdown (2005), a criança desde cedo tem capacidade de comunicar, prevalecendo a sua participação. Segundo a autora, pode ser analisada à luz de três processos, sendo estes: "consultivos, (...) quando os adultos reconhecem que as crianças têm a sua própria a opinião e experiências (...); participativos, oferecem oportunidades para que os meninos intervenham ativamente no desenvolvimento (...); autónomo, as crianças têm o poder de compreender a ação" (p. 16-18).

A participação da criança poderá ocorrer em múltiplos contextos, sejam sociais ou educativos, pois a criança tem direito à sua opinião, exprimindo livremente 0 seu ponto de vista (CDC, 2014, artigo $12^{\circ}$ e $13^{\circ}$ ). Neste processo de participação é fundamental, segundo Tomás e Gama (2011), a negociação entre os agentes, que por meio da partilha democrática de ideias resultam novos saberes.

Aquando das atividades verifica-se que a participação da criança provém, em grande parte, do interesse dos adultos. De acordo com Craveiro e Silva (2016), as instituições deverão potenciar a participação da criança, prevalecendo os seus direitos, e o profissional de educação deverá desenvolver o papel de mediador e construtor de oportunidades. Assim, será relativamente ao seu grau de participação em programas CATL, pois de acordo com Little, Wimer e Weiss, (2008), depende parcialmente, das escolhas dos familiares e dos filhos acerca do modo como vivenciam e experimentam o tempo. 0 que faz notar que a presença e decisão do adulto afeta, não só a educação escolar, como também a extraescolar.

\section{OBJETIVOS DA INVESTIGAÇÃO}

Com 0 intuito de orientar genericamente a investigação, acerca do papel das crianças e jovens no âmbito das atividades de tempos livres, traçou-se um objetivo geral "perceber qual o envolvimento da criança e jovem nas atividades de tempos livres" e três objetivos específicos: 1) compreender o grau de satisfação das crianças e jovens no desenvolvimento das atividades de tempos livres; 2) compreender o modo de participação das crianças e jovens no desenvolvimento das atividades de tempos livres; 3 ) entender as relações estabelecidas no âmbito das atividades de tempos livres, nomeadamente nas relações: criança-criança e criança-profissional.

\section{AMOSTRA}

No âmbito do plano de seleção de participantes em estudo, as unidades de análise foram constituídas por pessoas, com caraterísticas diferentes, mas todas com ligação direta ou indireta às valências dos CATL envolvidas. Nomeadamente, comtemplamos a seguinte amostra, constituída por ex-educandos/as ( $n=2)$, atuais educandos $(n=148)$, encarregados de educação $(n=6)$ e profissionais de educação ( $n=8$ : Professores $-n=2$; Animadores $-n=2$; Ajudantes $-n=4$ ). Foram selecionados por conveniência, interesse de participação e pelas suas caraterísticas pessoais (tempo e qualidade de relação com o CATL). É de salientar que a amostra da observação participante foram as crianças, dos 3 aos 12 anos de idade, que frequentavam os seis CATL em estudo. 


\section{Metodologia}

0 nosso estudo qualitativo apresenta caraterísticas de um estudo de caso, pois propusemos analisar numa determinada Instituição Particular de Solidariedade Social (IPSS) e seis valências CATL "Centros de Atividades de Tempos Livres".

0 modelo definido tem um enfoque qualitativo, pois o investigador pôde recolher dados em ambiente natural, com perceção de alguns pormenores (Bogdan \& Biklen, 1994). Os resultados terão validade apenas para a realidade que foi estudada.

$\mathrm{Na}$ recolha dos dados utilizou-se diferentes técnicas, tais como: análise documental; observação e entrevista (populações dos encarregados de educação, profissionais e educandos).

Numa primeira fase realizou-se uma observação exploratória. Posteriormente, com base numa grelha construída, realizou-se a observação participante, recolhendo-se informações dos pormenores, as ações e os diálogos, apostando numa interação e participação ativa, tendo como recurso imagens e/ou áudios (Bogdan \& Biklen, 1994). De forma a aprofundar e conhecer melhor o contexto e as pessoas realizou-se entrevistas - informais, semiestruturadas - individual e de grupo (Focus Group - FG) da discussão dos participantes e para a constituição do grupo a inquirir, incluímos 3 profissionais, 1 encarregado de educação e 2 ex-educandos, estando no papel de mediador o investigador.

No âmbito do estudo aplicou-se o consentimento informado à amostra bem como à instituição em estudo, salvaguardando a identidade e confidencialidade dos mesmos e restantes princípios éticos. Realizou-se a codificação de todas as informações e imagens/ áudios recolhidos, de forma a preservar os participantes no estudo.

Da análise de conteúdo, selecionaram-se unidades de registo e formaram-se categorias e subcategorias.

\section{RESULTADOS}

Após a recolha da informação apresenta-se os resultados obtidos, com base nos instrumentos utilizados. Fruto da análise de conteúdo das entrevistadas realizadas a profissionais e encarregados de educação construiu-se uma categorização, conforme 0 quadro n.․ 1 .

Analisando o mesmo pode-se depreender dos testemunhos dos profissionais sobre a "participação das crianças nas atividades", que elas têm uma excelente participação no CATL, nas atividades de sala e também nos eventos, verificando-se assiduidade, adesão e empenho. Segundo alguns entrevistados a participação das crianças também se deve, em parte, pelas multiatividades que a valência promove, ou seja, oferta educativa do CATL. 


\section{O IMPACTO DO BRINCAR/ JOGAR EM ATIVIDADES DE TEMPOS LIVRES NO ENVOLVIMENTO, SATISFAÇÃO E INTERAÇÃO DE CRIANÇAS E JOVENS}

\section{Quadro n.ำ1 - Análise de Conteúdo - Entrevistas Individuais - "Envolvimento nas atividades"}

\begin{tabular}{|c|c|c|}
\hline Categorias & $\begin{array}{l}\text { Subcate- } \\
\text { gorias }\end{array}$ & Unidades de registo selecionadas \\
\hline $\begin{array}{l}1 . \\
\text { Participação } \\
\text { nas ativida- } \\
\text { des }\end{array}$ & & $\begin{array}{l}\text { "...nós temos praticamente todas as salas lotadas, muitos pólos com lista de espera (...) o } \\
\text { nosso ATL é uma continuação da familia, não é só para pais que trabalham... Os números } \\
\text { falam por si, nós temos freguesias que quase } 80 \% \text { estão no ATL" (Prof_A) } \\
\text { "... Há crianças que participam em atividades e outras não, mas a gente tem uma ferra- } \\
\text { menta fantástica, a gente fala com o pai, a gente tenta falar com ele..." (Anim A) } \\
\text { "eles participam, porque eles estão aqui todos os dias, todos os dias eles vêm e todos os } \\
\text { dias tem coisas diferentes..." (Enc_Ed_C) } \\
\text { "... Há atividades que elas gostam porque elas sabem que a mãe não vai, que não tem } \\
\text { oportunidade para ir, se não fosse o CATL elas não iam" (Enc Ed E) }\end{array}$ \\
\hline $\begin{array}{l}2 . \\
\text { Satisfação } \\
\text { das crianças }\end{array}$ & & $\begin{array}{l}\text { "... as crianças e pais estão muito satisfeitos com os serviços... vemos o nível de satisfa- } \\
\text { ção na frequência diária, na forma como as crianças pedem para vir para o } \\
\text { CATL..." (Prof B) } \\
\text { "Eles adoram, eles querem o CATL, eles gostam das atividades, eles gostam das brincadei- } \\
\text { ras, eles gostam da interação com os colegas" (Anim_A) } \\
\text { "... se algum motivo a criança não estiver satisfeita e não estiver a correr bem temos de } \\
\text { mudar os planos para satisfazer a criança" (Ajud_A) } \\
\text { "... o ATL dá-lhes oportunidade deles usufruirem de determinadas coisas, determinadas } \\
\text { atividades que eles não conseguiam se estivessem em casa... que faz com que o grau de } \\
\text { satisfação deles ao frequentarem o ATL seja muito bom, é muito benéfico" (Ajud B) } \\
\text { "... aqui é a segunda casa deles ... E apesar deles reclamarem eles gostam" (Enc_Ed_C) } \\
\text { ".... Algum pode fazer uma "birra" isso é normal, como todos. Mas eles gostam muito e as } \\
\text { atividades muito boas eles gostam muito" (Enc Ed E) }\end{array}$ \\
\hline \multirow[t]{2}{*}{$\begin{array}{l}3 . \\
\text { Relações }\end{array}$} & $\begin{array}{l}3.1 \\
\text { Relações } \\
\text { com os } \\
\text { colegas }\end{array}$ & $\begin{array}{l}\text { "Nós promovemos sempre a ligação destes grupos e enriquecem muito o conhecimento } \\
\text { das crianças... o facto de conhecer mais pessoas, mais crianças enriquece-as enquanto } \\
\text { ser" (Prof_A) } \\
\text { "Algumas são mais amistosas e outras nem tanto, mas a criança tem uma aptidão natural } \\
\text { para se adaptar com facilidade às situações e aos pares, facilmente descobrem como intera- } \\
\text { gir uns com os outros e como lidar com as situações adversas, descobrem a sua própria es- } \\
\text { tratégia e conseguem adaptá-la e superá-la ..., não são relações muito conflituo- } \\
\text { sas..." (Prof_B) } \\
\text { "... principalmente os mais velhos. Já têm uma outra maturidade que depois querem incutir } \\
\text { nos mais novos, ao nivel de explicação de como é um jogo... estão em fase de aprendiza- } \\
\text { gem" (Anim_B) } \\
\text { "... digamos é o meu ajudante, é a minha mão direita..." (Anim_A) } \\
\text { "As crianças... eles conseguem ser muitos amigos, mas também conseguem ser muito } \\
\text { cruéis. Há esta dualidade das crianças ...." (Ajud_A) } \\
\text { ".... criança que é exposta a maior violência, claro que vai trazer para o CATL agressivi- } \\
\text { dade e violência .... uma criança que tem em casa um ambiente muito bom, claro que vai } \\
\text { ser uma criança muito mais calma e pacifica" (Ajud_A) } \\
\text { "... porque os mais velhos, cuidam especialmente dos meninos mais novos, sempre com } \\
\text { muito carinho e com crianças com dificuldades educativas especiais mais ainda" (Ajud A) }\end{array}$ \\
\hline & $\begin{array}{l}3.2 \text { Rela- } \\
\text { ções com } \\
\text { os profis- } \\
\text { sionais }\end{array}$ & $\begin{array}{l}\text { Daí que temos de ter uma postura muito aberta, temos que ouvir a todos (...) de ouvirmos a } \\
\text { todos, promover tempo para que as crianças se façam ouvir ... é desconstruir a imagem do } \\
\text { profissional rígido, que dá a ordem e a criança acata, não exprime a sua vonta- } \\
\text { de..." (Prof A) } \\
\text { "... é alguém em que podem confiar em tudo e também há a abertura do profissional para } \\
\text { estes momentos, de lazer, momentos de responsabilização, para o momento de convivio, } \\
\text { para momentos de chamada de atenção (...)" (Prof_B) } \\
\text { "... elas gostam que a gente entre nos jogos e tudo, ficam muito contentes" (Anim_A) } \\
\text { "somos o exemplo...." (Ajud_A) } \\
\text { c... se a profissional tem de respeitar as crianças sobre tudo eles também como nos conhe- } \\
\text { cem ter algum respeito por nós e não dizer o que lhes vai na cabeça" (Ajud_D) }\end{array}$ \\
\hline
\end{tabular}

Confrontando a análise do quadro $n . .1$ com as respostas e discussão sobre a "participação", na entrevista coletiva, verifica-se que consideram também que é importante haver a oferta de multiatividades, pois "se não houver atividades os pais também começam a reclamar" (ex Aluno_FG). Mediante 0 contexto, para alguns entrevistados, a atividade também representa uma importância diferente.

De acordo com a observação notou-se que as crianças apresentam um envolvimento muito harmonioso com o CATL, participando livremente nas atividades e eventos. Na concretização e envolvimento nas atividades as crianças e jovens têm uma atitude muito pró-ativa, na medida em que rea- 
lizam as mesmas de forma autónoma e responsável (Obs_1로_2aㅗ), pois "a participação das crianças é bastante positiva, revelando que gostam de participar nas atividades promovidas" (Obs_CATL_D_2으).

Com base na análise do quadro $n .-1$, pode-se verificar que a criança quer participar nas atividades e que, por vezes, os encarregados de educação não deixam. Verificou-se, ainda, que na participação das crianças os profissionais têm um papel ativo, pelo entusiasmo, pela valorização e pelo dinamismo que passam às mesmas. A participação nas atividades também é reconhecida por um entrevistado como sendo uma oportunidade de usufruir de momentos diferentes e enriquecedores,

Da discussão realizada em grupo alguns revelam que é importante respeitar a vontade de participação da criança, mas também "não se deixa de incentivar a criança a experimentar..." (Prof_B_FG). À semelhança das entrevistas individuais, os entrevistados referem que os pais têm um papel ativo na participação das crianças, pois “... elas querem, gostam, participam em tudo 0 que é atividade de preparação ... mas chega a concretização, o produto final e não está presente, porque os pais não permitiram..." (Prof_B_FG).

Aquando da observação, verificou-se que nas atividades de exterior as crianças brincaram de "forma muito feliz e entusiasmante" (Obs_CATL_D_1스). Face a esta atitude, pode-se deduzir que apesar de manifestarem o seu desagrado face a alguns momentos de participação, as crianças, depois, conseguem através do brincar, desenvolver uma outra atitude.

De acordo com a "satisfação das crianças", na totalidade todos os entrevistados revelaram que as crianças, assim como alguns pais, estão muito satisfeitas com o CATL, sendo também do seu agrado as relações estabelecidas com os colegas.

No grau de satisfação os profissionais também têm um papel importante, uma vez que pela observação verificou-se que se adaptam às atividades, dando flexibilidade às mesmas e, segundo alguns entrevistados, quando há pouca vontade da criança participar, há uma explicação e valorização das atividades e depois acabam por gostar.

De acordo com a observação notou-se que a satisfação das crianças é verificável "nas atividades de divertimento: de faz-de-conta (brincar às mães/ pais), jogos lúdicos (damas, cartas) e baloiço. Outro momento que diverte as crianças é a ida para o exterior" (Obs_CATL_B_1르). 0 que também motiva e impulsiona bastante a satisfação pelas atividades é 0 envolvimento dos profissionais, pois "é com satisfação que veem as senhoras a participarem com elas nas atividades" (Obs_CATL_B_1르).

No que diz respeito às "relações", com a subcategoria "relações com os colegas", na generalidade todos os entrevistados manifestaram que as relações contribuem positivamente para o desenvolvimento da criança, pois na relação com os colegas (criança-criança) nota-se uma parceria e companheirismo constante, seja na construção dos jogos, divisão de tarefas de expressões e dina-

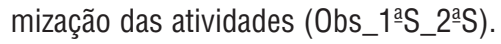

Contudo, alguns entrevistados referiram que há uma "dualidade das crianças", uma vez que há crianças que conseguem ser amigos uns com os outros, enquanto que outras crianças são mais "agressivas". Segundo os entrevistados, esta agressividade advém do contexto familiar das crianças e da exposição de violência que alguns estão sujeitos.

Tendo em linha de conta a análise do grupo discussão, entende-se que face à subcategoria "relações com os colegas" é importante "ir ao encontro" (Prof_B_FG) do grupo, das suas necessidades, idades e interesses, a fim de haver um envolvimento positivo. Este professor defende que é importante saber lidar com o conflito, pois "é muito cómodo ter crianças no computador porque não dá que fazer, não fazem barulho, não há riscos de se magoar, não estão a entrar em conflitos uns com os outros". Ou seja, nesta relação com os colegas é fulcral proporcionar às crianças atividades dife- 


\section{O IMPACTO DO BRINCAR/ JOGAR EM ATIVIDADES DE TEMPOS LIVRES NO ENVOLVIMENTO, SATISFAÇÃO E INTERAÇÃO DE CRIANÇAS E JOVENS}

rentes e em espaços pouco semelhantes, dotando-os de ferramentas essenciais para a gestão de relações interpessoais. É neste sentido que Vilhena (citado por Silva \& Sarmento, 2017) revela que, os CATL deverão ter como principais "objetivos a animação, a socialização de grupos e, acima de tudo, a satisfação da criança" (p. 49). Em 2004, Sequeira e Pereira também concluíram que as crianças valorizaram no CATL a presença dos seus amigos.

Realça-se também pela análise a valorização do trabalho de grupo e da partilha entre algumas crianças, pois a interação entre a criança mais nova e a criança mais velha (tutor) é vista por todas as entrevistadas como sendo muito positiva, uma vez que possibilita um maior envolvimento, acompanhamento, amizade, companheirismo e interajuda. 0 papel do tutor é fulcral não só para a criança mais nova, como também para o profissional, uma vez que serve de apoio e testemunho de regras e procedimentos. 0 mesmo foi corroborado durante a observação, o que segundo os profissionais é uma mais-valia, porque possibilita proximidade, proteção e constantes ensinamentos e partilha de diálogos (Obs_CATL_C_1 1 -S).

Segundo alguns entrevistados as relações entre as crianças acabam por influenciar as relações para além do tempo vivido no CATL, ou seja, criam-se amizades e cumplicidades que faz com que haja um círculo de amigos que derivaram da interação do CATL, por isso caraterizam-se como sendo um ambiente familiar. Pela observação confirmou-se as perceções dos entrevistados, pois "todos interagiam entre si, com afetos, cuidado e aceitação" (Obs_CATL_B_1르).

Nas "relações", possui outra subcategoria designada de "relações com os profissionais". Segundo a análise das entrevistas foi notória, por parte de todos os entrevistados, que o profissional de educação, em ambiente CATL, deverá ter um papel flexível e aberto, estando sempre atento às necessidades das crianças.

Face ao papel do profissional, os entrevistados referiram que é bastante positivo quando este se envolve nas atividades com as crianças, influenciando a sua motivação e entusiasmo. Craveiro e Silva (2016) referem que, o profissional de educação tem a possibilidade de criar um ambiente propício à participação e ao aparecimento de novas oportunidades, desenvolvendo uma relação de qualidade com a criança.

No grupo de discussão, os entrevistados referem que "cabe ao profissional ter esta capacidade para fazer esta adequação" (Prof_B_FG) para que a relação seja positiva e harmoniosa. De acordo com a observação registou-se que "as funcionárias revelam muita proteção e cuidado para com as crianças... as funcionárias brincaram com as crianças, com reação positiva pelas crianças" (Obs_CATL_B_1폭). Sequeira e Pereira (2004) afirmaram que as crianças apreciam a participação dos profissionais no âmbito das atividades de tempos livres, porém estes deverão fazê-lo com gosto e interesse.

Em geral os entrevistados afirmaram que o profissional no âmbito das suas funções deverá ouvir as crianças, proteger, resolver os conflitos surgidos e proporcionar momentos de lazer. De acordo com Araújo (2009), há a preocupação dos profissionais dos CATL prepararem as crianças para a vida adulta, dotando-as de capacidades, meios e oportunidades educativas, em 2004, a mesma autora designou os profissionais de "agentes de desenvolvimento local, mediadores por excelência" (pp. 27-28).

De forma a sintetizar o ponto do nosso estudo sobre "o papel das crianças e jovens nas atividades de tempos livres", através da informação obtida no cruzamento dos dados dos vários instrumentos apresentados no esquema síntese (figura 1). 
Figura 1: Esquema síntese do conceito "Envolvimento da criança e do jovem"

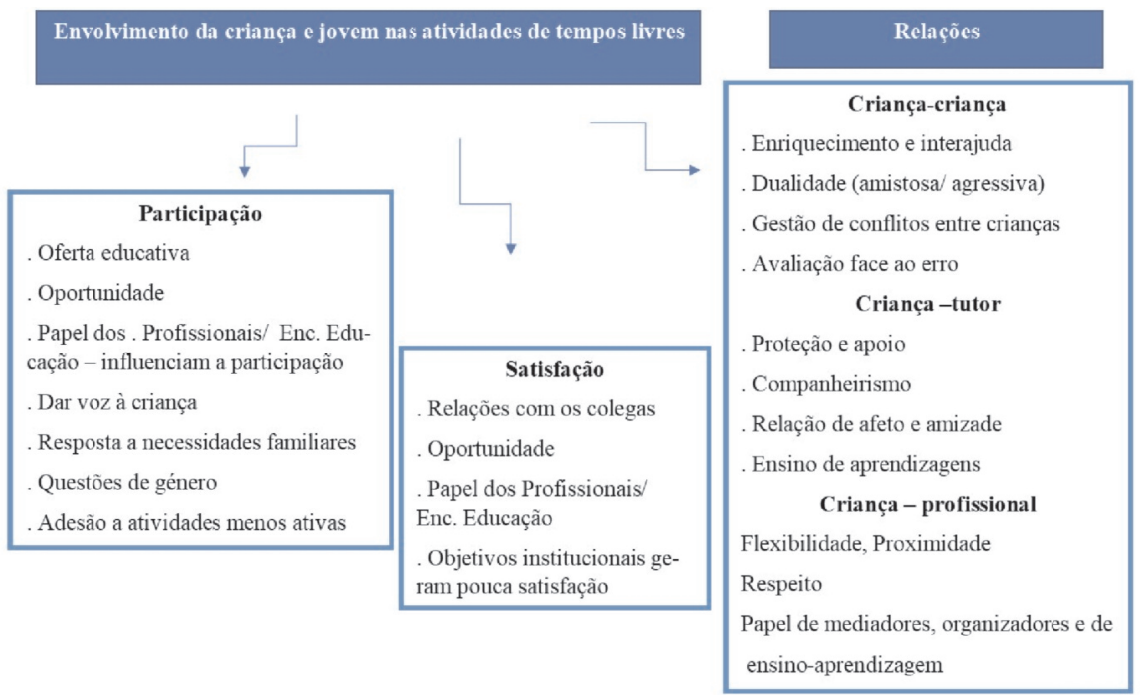

Para Sarmento (2015), as instituições educativas deverão promover o acesso aos direitos da criança - proteção, saúde, educação, lazer, identidade, alimentação, segurança, proteção. Condessa (2017) reforça a ideia que o jogo e a brincadeira deverão ser contemplados nesses contextos por serem reconhecidos como tendo elevada importância no desenvolvimento da criança. Só assim, a criança tem a possibilidade, através da participação nas atividades, de usufruir de novas oportunidades (maior oferta educativa), que vão ao encontro do interesse e satisfação da própria criança. Segundo V. Pereira, Condessa e B. Pereira (2017), é adaptável a estas instituições, pois os profissionais de educação têm a possibilidade de fazer prevalecer na criança 0 direito à brincadeira e ao jogo livre, com vista ao desenvolvimento de competências físicas e cognitivas.

\section{CONCLUSÕES}

Na linha final do presente estudo acerca da investigação sobre o papel das crianças e jovens nas atividades de tempos livres nas dimensões - satisfação, participação e relações, sublinham-se as principais conclusões:

excelente participação das crianças e profissionais nas multiatividades, mediante satisfação e interesse pela dinamização das mesmas;

existência de atividades que tendem a corresponder a interesses institucionais. Tais atividades têm, por vezes, a sua primazia nos interesses da instituição, devido a obrigações e a parcerias legais; esforço de adequação das atividades às crianças. Por parte dos profissionais há a preocupação em responder aos interesses e gostos das crianças, adequando as atividades ao desenvolvimento das mesmas;

as crianças possuem um relacionamento harmonioso, com os colegas (mais velhos e mais novos), com vista a desenvolver atividades de autonomia, responsabilidade e empenho;

a relação das crianças com os profissionais, norteada pela amizade e atenção face às necessidades das mesmas (sociais e familiares). 0 papel dos profissionais deverá ser de mediação e de 


\section{O IMPACTO DO BRINCAR/ JOGAR EM ATIVIDADES DE TEMPOS LIVRES NO ENVOLVIMENTO, SATISFAÇÃO E INTERAÇÃO DE CRIANÇAS E JOVENS}

proteção face às relações estabelecidas com as crianças, desenvolvendo condições propicias à aprendizagem.

Crê-se, com este trabalho, que criança precisa de liberdade para crescer, explorar o mundo e relacionar-se de forma feliz, pois se for coagida e pressionada não consegue "deixar fluir plenamente a imaginação, a fantasia, o prazer, a repetição, a criatividade, a alegria" (Costa, et al., 2015, p. 408), uma vez que ela precisa de espaço e tempo para os seus próprios ritmos e aprendizagens, usufruindo de um dos seus principais direitos, a liberdade (Convenção dos Direitos da Criança, 2004). Para Costa et al., (2015), as crianças precisam do seu próprio tempo, para traçar o seu rumo e fazer as suas escolhas, sendo necessário haver por parte do adulto a valorização deste tempo. Neste sentido, os CATL, da IPSS em estudo, assentam na gestão no enfoque principal no brincar, enquanto constructo de desenvolvimento pessoal, social e educativo da criança/ jovem.

\section{REFERÊNCIAS BIBLIOGRÁFICAS}

Araújo, M. J. (2004). Atividades de tempos livres - tempo livre vs tempo ocupado. Dissertação não publicada. Faculdade de Psicologia e de Ciências da Educação da Universidade do Porto, Porto.

Araújo, M. J. (2006). Crianças sentadas! Os trabalhos de casa no ATL. Porto: Livpsic.

Araújo, M. J. (2009a). Crianças ocupadas: como algumas opções erradas estão a prejudicar os nossos filhos. Porto: Prime Books.

Bogdan, R., \& Biklen, S. (1994). Investigação qualitativa em educação: uma introdução à teoria e aos métodos. Porto: Porto Editora.

Condessa, I. C. (2017). Olhares sobre o papel do jogo nas aprendizagens escolares relatos de estagiários a educadores de infância e professores do 1ํㅡㄹ. In J. Pinhal, F. A. Costa, \& A. R. Faria (Orgs.), Atas do XIII Colóquio da AFIRSE Portugal: As pedagógicas na sociedade contemporânea: desafios às escolas e aos educadores (pp. 266- 276). Lisboa: AFIRSE Portugal - Instituto de Educação da Universidade de Lisboa.

Convenção dos Direitos das Crianças. (2004). Unicef. Recuperado de https://www.unicef.pt/ docs/pdf_publicacoes/convencao_direitos_crianca2004.pdf.

Costa, A. R., Kuhn, R., \& Cunha, A. C. (2015, julho). Sem tempo para brincar: as crianças, os adultos e a tirania dos relógios. Comunicação apresentada no Congresso XI Seminário Internacional de Educação Física, Lazer e Saúde - Perspetivas de Desenvolvimento num Mundo Globalizado, Escola Superior de Educação - Instituto Politécnico do Porto. Recuperado de: http://hdl.handle.net/1822/39653.

Craveiro, C., \& Silva, B. (2016). A consideração pela opinião da criança em contextos e quotidianos de educação de infância. In F. I. Ferreira, C. I. Anjos, A. A. Duarte, E.

Fernandes, N. H. R. Franco, S. E. Santos, \& T. Sarmento (Orgs.), Atas do II Seminário LusoBrasileiro de Educação de Infância: Investigação, formação docente e culturas da infância (pp. 92-103). Santo Tirso: Whitebooks. Recuperado de http://media.wix.com/ugd/c875f7_ 3ebce3a1a52441a0b77c651730c34809.pdf

Lansdown, G. (2005). Me haces caso? El derecho de los niños pequeños a participar en las decisiones que los afectam. Cuadernos sobre Desarrollo Infantil Temprano, (36), 1-60.

Little, P. M. D., Wimer, C., \& Weiss, H. B. (2008). Aflter school programs in the $21^{\text {st }}$ Century: Their potential and what it takes to achieve it. Issues and Opportunities in out-of-school time evaluation, 10, 1-21. Recuperado de http://most.ie/webreports/After $\% 20$ School\% 20Programs \%20whayt\%20is\%20takesHFR.pdf

Neto, C. (2000). 0 jogo e o tempo livre nas rotinas de vida quotidiana de crianças e jovens. In Câmara Municipal de Lisboa - Departamento de Acção Social (Orgs.), Seminário de Tempos Livres: A Criança, o Espaço, a Ideia (pp. 11-20). Lisboa: Câmara Municipal de Lisboa. 
Recuperado de https://scholar.google.pt/scholar?hl=ptPT\&as_sdt=0\%2C5\&q=0+jogo+e+0+ tempo+livre+nas+rotinas+de+vida+quotidiana+de+crian\%C3\%A7as+e+jovens\&btnG=.

Neto, C. (2004). 0 desenvolvimento da motricidade e as "culturas da infância". In W. Moreira, \& R. Simões (Orgs.), Educação física: Intervenção e conhecimento científico (pp. 2-13). Piracicaba Brasil: Editora Unimep. Recuperado de https://scholar.google.pt/scholar?hl=ptPT\&as_sdt $=0,5 \& q=0+d e s e n v o l v i m e n t 0+d a+$ motricidade $+e+a s+\% E 2 \% 80 \% 9 C$ culturas + da + inf $\%$ C3\%A2ncia\%E2\%80\%9D.

Pereira,V., Condessa, I., \& Pereira, B. (2017). Educadores em ação no recreio escolar: formar para (inter) agir. In J. A. F. P. Júnior (Org.), Conhecimentos do professor de Educação Física Escolar (pp: 622-653). Fortaleza-CE: Ed. UECE. Recuperado de http://www.uece.br/eduece/dmdocuments/Conhecimentos\%20do\%20professor\%20de\%20Educaca0\%20Fisica\%20escolar.pdf

Sarmento, M. J. (2003). Imaginário e Culturas da Infância. Texto produzido no âmbito das Atividades do Projeto "As Marcas dos Tempos: Interculturalidade nas Culturas da Infância". Projeto POCTI/ CED/ 49186/ 2002, financiado pela Fundação para a Ciência e a Tecnologia. Instituto de Estudos da Criança, Universidade do Minho. Recuperado de http://www.cedic.iec.pt/ Textos_de_Trabalho/textos/ImaCultInfancia.pdf

Sarmento, M. J. (2011). A reinvenção do ofício de criança e de aluno. Atos de pesquisa em educação, 6(3), 581-602. doi: 10.7867/1809-0354.2011v6n3p581-602.

Sarmento, M. J. (2015). Para uma agenda de educação de infância em tempo integral assente nos direitos da criança. In V. C. Araújo (Org.), Educação Infantil em jornada de tempo integral: dilemas e perspetivas (pp. 61-89). Vitória: Edufes. Recuperado de http://hdl.handle.net/1822/36770.

Sequeira, A., \& Pereira, B. (2004, setembro). Estudo descritivo das actividades de tempos livres no ATL: um estudo de caso. Comunicação apresentada no VIII Congresso Luso-Brasileiro de Ciências Sociais, Coimbra.

Silva, M. C., \& Sarmento, T. (2017). 0 brincar na infância é um assunto sério.... In T. Sarmento, F. I. Ferreira, \& R. Madeira (Orgs.), Brincar e aprender na infância (pp. 39-56). Porto: Porto Editora.

Soares, N. F. (2005). Os Direitos das crianças nas encruzilhadas da proteção e da participação. Zeroa-Seis, 7(12), 8-18.

Tomás, C., \& Gama, A. (2011, janeiro). Cultura de (não) participação das crianças em contexto escolar. Comunicação apresentada no II Encontro de Sociologia da Educação: Educação, Territórios e (Des) Igualdades, Porto.

Tomás, C. (2007). Paradigmas, imagens e conceção da infância em sociedade mediatizadas. Media \& jornalismo, (11), 119-134. 
